\title{
DYNAMIC SIMULATION OF MULTINARY DIFFUSION PROBLEMS RELATED TO SOIL
}

\section{P. A. LEFFELAAR ${ }^{1}$}

A dynamic simulation model describing diffusion of gases in multinary gas mixtures was developed to calculate the interdiffusion of gases in complex systems where respiration and denitrification take place. The model is based on the StefanMaxwell equations for concentration diffusion of isothermal, isobaric ideal-gas mixtures and applies to a one-phase system in one dimension. To test the correct implementation of the theory in the model, it was used to calculate the mole fraction distribution in a gas layer for some ternary diffusion problems for which analytical solutions to the steady-state situation are known. Agreement between numerical and analytical solutions was within $1 \%$. Subsequently, the model was used to calculate the dynamic behavior of a gas system in which denitrification takes place and acetylene is used to prevent the conversion of nitrous oxide into molecular nitrogen. When a $2 \%$ concentration of acetylene was maintained at the surface of the gas layer, and biological activity was positioned at a depth of $0.25 \mathrm{~m}$, these calculations showed the acetylene concentration to reach $1.8 \%$. This value is sufficiently high to inhibit nitrous oxide conversion into molecular nitrogen, but would be equal to $2 \%$ when calculated on the basis of Fick's law. A simplified approach to calculate diffusion in multinary gas mixtures is proposed and tested for the case study of denitrification. It turns out that results of the simplified approach approximate those of the StefanMaxwell equations to within $10 \%$. The objectives of this paper are to discuss the model, to compare the results of the numerical and analytical solutions of two ternary diffusion problems, to report the results of the case study of denitrification, and to compare these results with those obtained from simplified diffusion theory.

${ }^{1}$ Agricultural Univ. Wageningen, Dept. of Theoretical Production Ecology, Bornsesteeg 65, 6708 PD Wageningen, the Netherlands.

Received for publication 30 July 1985; revised 19 February 1986.
Exchange of gases between soil and atmosphere is of great importance with regard to biological activity of, for example, (micro-)organisms and plant roots in soil. The physical processes causing gas movement are convection and diffusion. Convection occurs when a spatial difference in absolute gas pressure exists, e.g., after a heavy rainfall (Flühler and Läser 1975) or atmospheric variations in pressure and temperature (Kraner et al. 1964), or due to formation of gaseous products from nongaseous substrates (Stolzy and Flühler 1978). Diffusion occurs when there is a spatial difference in the partial pressures of components in a mixture of gases.

Diffusion in multinary gas mixtures like soil atmosphere cannot exactly be described by Fick's law (Jaynes and Rogowski 1983; Wood and Greenwood 1971). This law assumes that gas fluxes can be calculated independently of each other as concentration gradient times diffusion coefficient. In fact, Fick's law is a special case of the results obtained by the gas kinetic theory for multinary gas mixtures (Hirschfelder et al. 1964, p. 519). Gas kinetic theory shows gas fluxes due to diffusion to be coupled. Thus, gas diffusion of, for example, oxygen and carbon dioxide due to respiration does influence the distribution of an inert gas as nitrogen. As far as is known to the author, no mathematical solutions are available to study the dynamics of the gas phase of soil as a whole. Therefore, a simulation model to describe the dynamics of diffusion in multinary gas mixtures with source/ sink terms based on results of the gas kinetic theory as given by Hirschfelder et al. (1964) was developed. This model applies to diffusion processes in soil when the mean free path between intermolecular collisions (a characteristic value is $0.07 \mu \mathrm{m}$ for air-gases at $293 \mathrm{~K}$ and $1 \mathrm{~atm}$ ) is not much more than one-hundredth of the gasfilled pore diameters (Wakao et al. 1965) (a characteristic value is $28 \mu \mathrm{m}$ for well-drained soils at $\mathrm{pF}=2$, when calculated from the simple capillary model, Koorevaar et al. 1983). The model does not include the influence of tortuosity and area reduction on diffusion, as these 
depend merely on characteristics of the porous medium (Wakao and Smith 1962).

The mathematics of multinary gas diffusion will be seen to be rather involved. Therefore, a simplified approach to calculate diffusion in multinary gas mixtures is proposed.

The objectives of this paper are to describe the multinary dynamic gas diffusion model, to compare some of the model results with known analytical solutions to ternary steady-state diffusion problems, and then to use the model to calculate the dynamic behavior of a gas system in which denitrification takes place and acetylene is used to inhibit the conversion of nitrous oxide into molecular nitrogen. Finally, the simplified description of multinary diffusion is tested for the case study of denitrification.

\section{SIMULATION MODEL BASED ON THE STEFAN- MAXWELL EQUATIONS}

The equations describing the diffusion velocity of gas $j, \bar{V}_{j}$, relative to the diffusion velocity of gas $i, \bar{V}_{i}$, in a $v$-component isothermal, isobaric ideal-gas mixture for a one-phase system in one dimension for ordinary diffusion are (Hirschfelder et al. 1964, p. 517)

$$
\begin{aligned}
\sum_{\substack{j=1 \\
j \neq i}}^{v} \frac{n_{i} n_{j}}{n^{2} D_{i j}}\left(\bar{V}_{j}-\bar{V}_{i}\right)=\frac{d}{d x}\left(\frac{n_{i}}{n}\right), \quad \text { for } i \\
=1,2, \cdots, v
\end{aligned}
$$

All symbols for this and other equations are defined in the appended list of symbols. These $v$ so-called Stefan-Maxwell equations (Cunningham and Williams 1980, p. 109) form a set of $(v-1)$ independent equations, since

$$
\sum_{i=1}^{v}\left(n_{i} / n\right)=1
$$

Equation (1) can be used to obtain $(v-1)$ values of the diffusion velocities relative to any particular one. An additional equation that relates all fluxes is necessary to obtain all the diffusion velocities. Equation (1) has been used successfully to describe experimental data (Wilke 1950; Fairbanks and Wilke 1950). Further, a number of analytical solutions for steady-state diffusion problems using various boundary conditions have been published, by, among others, Toor (1957) and Hsu and Bird (1960).

In process calculations it is convenient to relate molar fluxes $\left(N_{i}\right)$ to stationary coordi- nates, rather than calculating diffusion velocities relative to one another. Further, to calculate the spatial distribution of gases, the space coordinate of the system to be simulated is divided into a number of layers, Fig. 1 (Frissel and Reiniger 1974; de Wit and van Keulen 1975). The principal equation used in the simulation model is obtained as follows. In an isothermal, isobaric ideal-gas mixture, total molecular concentration is constant, so $n$ in the spatial derivative and in the left-hand side of Eq. (1) cancels. Then, replace in Eq. (1) $\bar{V}_{i}$ by $\bar{v}_{i}-v_{0}=\left(N_{i} / c_{i}\right)$ - $v_{0}, n_{i}$ by $c_{i} \tilde{N}$ and $n$ by $c \tilde{N}$, write out the $v$ equations for $v$ terms, and rearrange to obtain a set of $v$ linear equations in terms of the products of each individual molar flux $\left(N_{i}\right)$ times its coefficient. Finally, write down the results in matrix notation for a layered system to obtain Eq. (2)

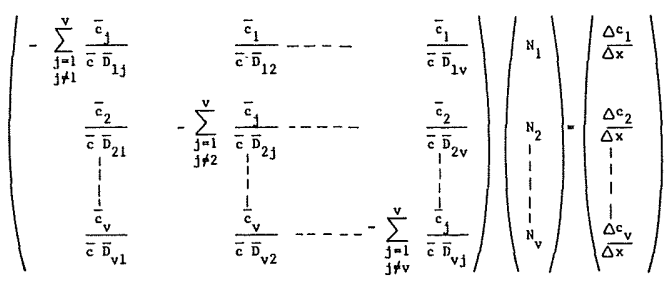

where bars above and $\Delta$ 's before symbols indicate, respectively, the arithmetic spatial average and the finite difference of that symbol, both with respect to the layers $L$ and $(L-1)$ of the system. As only $(v-1)$ equations are independent, the determinant of the matrix of coefficients in Eq. (2) equals zero. However, the system can be resolved when proper additional equations are defined. For instance, if the sum of the molar

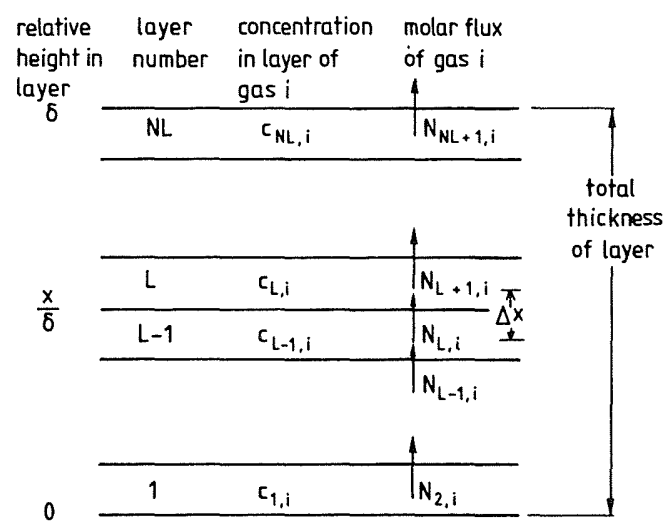

FIG. 1. Geometry of gas layer. Direction of flow is positive upward. 
fluxes through each interface is equal to zero, one of the rows (e.g., the first one) in the matrix of coefficients can be replaced by $1 \mathrm{~s}$ and the corresponding right-hand-side element by 0 . The sum of the molar fluxes through each interface is equal to 0 if a soil is exposed at its surface to constant concentrations of $\mathrm{O}_{2}, \mathrm{CO}_{2}$, and $\mathrm{N}_{2}$, while at some depth a constant but different concentration of $\mathrm{O}_{2}$ and $\mathrm{CO}_{2}$ exists due to equimolar respiration (example 2 in "Model Tests," below).

Essentially, at each time step, the model calculates on the basis of the gas concentrations present at the boundaries and in the layers of the system, the concentration gradients (righthand side of Eq. (2)) and all the coefficients of the matrix (left-hand side of Eq. (2)), except those in the first row. Then, the Gauss-Jordan elimination method (La Fara 1973, p. 119) is used to obtain the interlayer molar fluxes. From these, the net flux of each gas to each layer is calculated, and the molar equations of continuity with production terms

$$
\frac{\partial c_{i}}{\partial t}=-\frac{\partial N_{i}}{\partial x}+P_{i}
$$

are solved by integration over a time interval that is sufficiently small to maintain stability. Thus, the new molar distribution of gases over the layers is known. By repeating this procedure, the dynamic behavior of the model can be examined. Equation (2) can not be solved by the Gauss-Jordan algorithm when a certain gas is absent, because a zero pivot element will be found. This occurs when a gas has not yet diffused throughout the layer. Figure 2 gives the flowchart of the heart of the program that processes such zero gas concentrations. First it is checked which gases are present at a layer interface, and second the gases present are rearranged to obtain a matrix of nonzero elements in Eq. (2). Then the Gauss-Jordan elimination method is used to obtain the interlayer molar fluxes, and these results are rearranged in the original storage locations. The process is repeated for each layer interface in case all gases may diffuse throughout the layer; see example 2 in "Model Tests," below. In other options included in the model, the calculations for layer 1 are made differently as discussed in the examples. Other options included are: (1) one gas can diffuse throughout the gas layer; others experience an absorption barrier at the bottom (see

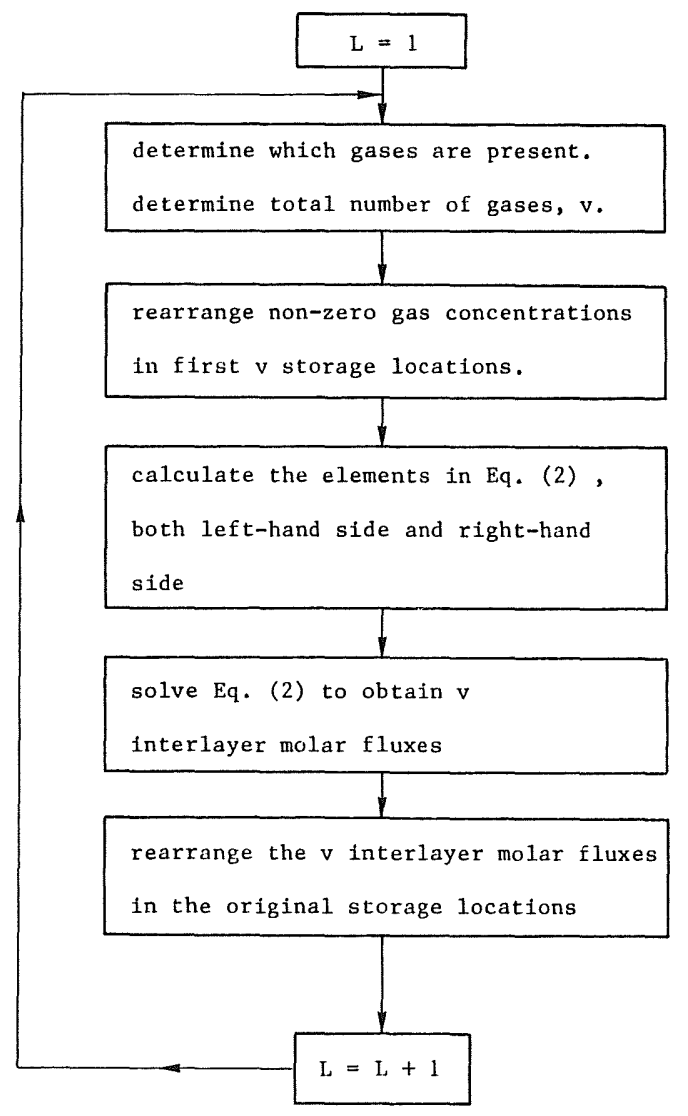

Fig. 2. Flowchart of the program section that processes zero gas concentrations.

example 1 in "Model Tests"); (2) one gas is converted into another gas in the bottom layer by some irreversible reaction, while the other gases cannot diffuse through the bottom layer; stoichiometry of reaction may be chosen as desired; (3) a maximum of six gas fluxes may be imposed to the bottom part of the gas layer; (4) a module containing the kinetics of the case study of denitrification as discussed in this paper.

The gas layer has a linear geometry as depicted in Fig. 1. The binary diffusion coefficients in Eq. (2) are calculated from theoretical equations (Hirschfelder et al. 1964) discussed below.

Numerical calculations are done by a program written in Continuous System Modeling Program III (CSMP III) language (IMB 1975) and executed on a DEC-10 machine. This language was chosen because of the availability of sophisticated methods of integration, e.g., the variable time-step methods that generally combine ac- 
curate solutions to the problem and lower computer times compared with fixed time-step methods. All results presented have been obtained by the variable time-step method of Runge-Kutta Simpson.

The program gives results in terms of the distribution in space and time of mole fractions, interlayer molar diffusion fluxes, and cumulative in or outflow of moles of gas at $x=0$ and $x=\delta$.

\section{BINARY DIFFUSION COEFFICIENTS}

Molar diffusion fluxes are directly proportional to binary diffusion coefficients, $D_{i j}$, thus demanding reliable estimates of these. If possible, accurate measurements of $D_{i j}$ s should be used in the calculation of fluxes. But even the very extensive compilation of diffusion coefficients by Marrero and Mason (1972) does not give all binary combinations of gas pairs that would be needed, for instance between $\mathrm{Ar}, \mathrm{O}_{2}$, $\mathrm{N}_{2}, \mathrm{CO}_{2}$, air, $\mathrm{H}_{2} \mathrm{O}$-vapor, $\mathrm{NH}_{3}, \mathrm{~N}_{2} \mathrm{O}, \mathrm{CH}_{4}$, and $\mathrm{C}_{2} \mathrm{H}_{2}$. The Chapman-Enskog theory, however, gives expressions to calculate binary diffusion coefficients under the following assumptions: (1) only binary elastic collisions between molecules, (2) a small mean molecular free path compared with the dimensions of the gas container, and (3) small concentration gradients (Hirschfelder et al. 1964). The composition dependence of binary diffusion coefficients is usually less than 5\% (Marrero and Mason 1972). Therefore, this effect is not considered, and the following expression is used (Hirschfelder et al. 1964, p. 539)

$$
D_{i j}=\frac{3}{8}\left(\frac{k^{3} \tilde{N}}{\pi}\right)^{1 / 2} \frac{\left[T^{3}\left(M_{i}+M_{j}\right) /\left(2 M_{i} M_{j}\right)\right]^{1 / 2}}{p \sigma_{i j}^{2} \Omega_{i j}}
$$

In Eq. (4) $M_{i} M_{j} /\left(M_{i}+M_{j}\right)$ is the reduced molecular weight of a pair of unlike molecules. The dynamics of collisions between molecules is represented by the dimensionless collision integral $\Omega_{i j}$. The physical meaning of the dimensionless collision integral is that it indicates the deviation of a particular molecular model from the idealized rigid-sphere model. For the numerical evaluation of the collision integral, a relationship between the potential energy of interaction and the intermolecular separation distance is needed. To this purpose the Lennard-Jones potential model is used. This potential model contains two parameters or force constants that are characteristics of the colliding molecules, i.e., $\sigma_{i i}$ and $\epsilon_{i i} . \sigma_{i i}$, with dimension of length, is the value of the intermolecular separation distance where the potential energy is zero and may be considered as the effective molecular size, compared with an ideal rigid-sphere model (Marrero and Mason 1972). $\epsilon_{i i}$ is the maximum energy of attraction occurring between molecules. For more details the reader is referred to Hirschfelder et al. (1964). The dimensionless collision integral is dependent on temperature and is usually tabulated as a function of reduced temperature $T_{i j}$ $\left(=k T / \epsilon_{i j}\right)$. The force constants between unlike nonpolar molecules, $\sigma_{i j}$ and $\epsilon_{i j} / k$, are obtained from empirical combining laws, i.e., the arithmetic mean for the collision diameter

$$
\sigma_{i j}=\left(\sigma_{i i}+\sigma_{j j}\right) / 2
$$

and the geometric mean for the maximum energy of attraction

$$
\epsilon_{i j} / k=\left[\left(\epsilon_{i i} / k\right)\left(\epsilon_{j j} / k\right)\right]^{1 / 2}
$$

For all practical purposes, however, Eqs. (5) and (6) may also be used to calculate these values between polar and nonpolar molecules (Mason and Monchick 1962). The constant $3 / 8$ $\left(k^{3} \tilde{N} / \pi\right)^{1 / 2}$ in Eq. (4) equals $8.4210^{-24}\left[J^{3} \mathrm{~K}^{-3}\right.$ $\left.\mathrm{mol}^{-1}\right]^{1 / 2}$. Equation (4) is symmetrical in $i$ and $j$ and reduces to the equation for a single component when properties of identical molecules are used, thus yielding the coefficient of self-diffusion (Hirschfelder et al. 1964, p. 539). This result is used in the case study of denitrification where nitrogen originating from denitrification is distinguished from atmospheric nitrogen.

Table 1 shows the fair agreement between binary diffusion coefficients calculated from Eqs. (4) through (6) and those calculated by an empirical equation given by Marrero and Mason (1972)

$$
\ln \left(p D_{i j}\right)=\ln a+b \ln T-c / T
$$

Equation (7) is to be used at reduced temperatures above unity. The calculations have been performed at 10 and $20^{\circ} \mathrm{C}$ for gas pairs that are of interest to soil research. Uncertainty limits given pertain to results of the empirical equation. The last column in Table 1 presents the percentages of deviation of results obtained by Eqs. (4) through (6) with respect to those of Eq. (7) at $10^{\circ} \mathrm{C}$; deviations at $20^{\circ} \mathrm{C}$ are of the same magnitude and are therefore not given. The theoretical values stay within the uncertainty 
TABLE 1

Comparison of binary diffusion coefficients obtained from theory with those estimated from regression analysis of experimental data for a number of gas pairs

\begin{tabular}{|c|c|c|c|c|c|c|}
\hline \multirow{3}{*}{ Gas pair ${ }^{a}$} & \multicolumn{4}{|c|}{$\begin{array}{l}\text { Binary diffusion coefficients } \\
D_{i j} \times 10^{4} \mathrm{~m}^{2} \mathrm{~s}^{-1}\end{array}$} & \multirow{3}{*}{$\begin{array}{l}\text { Uncertainty } \\
\text { limits, }{ }^{b} \%\end{array}$} & \multirow{3}{*}{$\begin{array}{l}\text { Deviations of } \\
\text { results of } \\
\text { Eqs. (4) } \\
\text { through (6) } \\
\text { from those of } \\
\text { Eq. (7) at } \\
10^{\circ} \mathrm{C}, \%\end{array}$} \\
\hline & \multicolumn{2}{|c|}{$\begin{array}{l}\text { After Hirschfelder et } \\
\text { al. (1964) (Eqs. (4) } \\
\text { through (6)) }\end{array}$} & \multicolumn{2}{|c|}{$\begin{array}{c}\text { After Marrero and } \\
\text { Mason (1972) } \\
\text { (Eq. (7)) }\end{array}$} & & \\
\hline & $10^{\circ} \mathrm{C}$ & $20^{\circ} \mathrm{C}$ & $10^{\circ} \mathrm{C}$ & $20^{\circ} \mathrm{C}$ & & \\
\hline $\mathrm{Ar}-\mathrm{CH}_{4}$ & 0.1909 & 0.2034 & 0.1865 & 0.1985 & 3 & 2.4 \\
\hline $\mathrm{Ar}-\mathrm{N}_{2}$ & 0.1763 & 0.1875 & 0.1785 & 0.1897 & 2 & -1.2 \\
\hline $\mathrm{Ar}-\mathrm{O}_{2}$ & 0.1765 & 0.1879 & 0.1763 & 0.1872 & 3 & 0.1 \\
\hline Ar-air & 0.1762 & 0.1876 & 0.1781 & 0.1892 & 3 & -1.1 \\
\hline $\mathrm{Ar}-\mathrm{CO}_{2}$ & 0.1272 & 0.1357 & 0.1379 & 0.1476 & 3 & -7.8 \\
\hline $\mathrm{CH}_{4}-\mathrm{N}_{2}$ & 0.1976 & 0.2103 & 0.1953 & 0.2075 & 3 & 1.2 \\
\hline $\mathrm{CH}_{4}-\mathrm{O}_{2}$ & 0.1997 & 0.2128 & 0.2057 & 0.2193 & 3 & -2.9 \\
\hline $\mathrm{CH}_{4}$-air & 0.1980 & 0.2108 & 0.1977 & 0.2101 & 3 & 0.2 \\
\hline $\mathrm{N}_{2}-\mathrm{O}_{2}$ & 0.1867 & 0.1987 & 0.1905 & 0.2023 & 3 & -2.0 \\
\hline $\mathrm{N}_{2}-\mathrm{H}_{2} \mathrm{O}$ & 0.2065 & 0.2208 & 0.2249 & 0.2417 & 4 & -8.2 \\
\hline $\mathrm{N}_{2}-\mathrm{CO}_{2}$ & 0.1383 & 0.1473 & 0.1490 & 0.1596 & 2 & -7.2 \\
\hline $\mathrm{O}_{2}-\mathrm{H}_{2} \mathrm{O}$ & 0.2079 & 0.2225 & 0.2273 & 0.2442 & 7 & -8.5 \\
\hline $\mathrm{O}_{2}-\mathrm{CO}_{2}$ & 0.1369 & 0.1460 & 0.1484 & 0.1584 & 3 & -7.7 \\
\hline Air- $\mathrm{H}_{2} \mathrm{O}$ & 0.2067 & 0.2210 & 0.2249 & 0.2417 & 5 & -8.1 \\
\hline Air- $\mathrm{CO}_{2}$ & 0.1378 & 0.1469 & 0.1489 & 0.1593 & 3 & -7.5 \\
\hline $\mathrm{H}_{2} \mathrm{O}-\mathrm{CO}_{2}$ & 0.1461 & 0.1566 & 0.1482 & 0.1620 & 10 & -1.4 \\
\hline $\mathrm{CO}_{2}-\mathrm{N}_{2} \mathrm{O}$ & 0.0982 & 0.1049 & 0.1056 & 0.1127 & 3 & -7.0 \\
\hline $\mathrm{O}_{2}-\mathrm{N}_{2} \mathrm{O}$ & 0.1376 & 0.1468 & - & - & - & - \\
\hline $\mathrm{O}_{2}-\mathrm{C}_{2} \mathrm{H}_{2}$ & 0.1472 & 0.1569 & - & - & - & - \\
\hline $\mathrm{N}_{2}-\mathrm{N}_{2} \mathrm{O}$ & 0.1391 & 0.1483 & - & - & - & - \\
\hline $\mathrm{N}_{2}-\mathrm{C}_{2} \mathrm{H}_{2}$ & 0.1476 & 0.1573 & - & - & - & - \\
\hline $\mathrm{C}_{2} \mathrm{H}_{2}-\mathrm{CO}_{2}$ & 0.1084 & 0.1159 & - & - & - & - \\
\hline $\mathrm{C}_{2} \mathrm{H}_{2}-\mathrm{N}_{2} \mathrm{O}$ & 0.1082 & 0.1157 & - & - & - & - \\
\hline
\end{tabular}
(7).

${ }^{a}$ For the same sequence of gas pairs, Jaynes and Rogowski (1983) have listed the constants $a, b$, and $c$ of Eq

${ }^{b}$ Uncertainty limits for $D_{i j}$ pertain to results calculated after Marrero and Mason (1972).

limits of the empirical values except for gas pairs involving $\mathrm{CO}_{2}$ or $\mathrm{H}_{2} \mathrm{O}$, where deviations are larger by a factor of 2 to 3 . Nevertheless, all deviations remain well within $10 \%$. Furthermore, the temperature dependence of the reported binary diffusion coefficients in the trajectory 10 to $20^{\circ} \mathrm{C}$ amounts on the average to 6.7 and $6.9 \%$ for the theoretical and empirical values, respectively. The binary diffusion coefficients for the last six gas pairs in Table 1, needed in the case study of denitrification, were not reported by Marrero and Mason (1972).

As the force constants $\sigma_{i i}$ and $\epsilon_{i i}$ are available for many gas molecules, applicability of the theoretical equations is very broad, compared with the experimental data given by Marrero and Mason (1972). Therefore, Eqs. (4) through (6) are used throughout this work.

The force constants and molecular weights for a number of gases of interest to soil aeration research are listed in Table 2. Numerical values for the dimensionless collision integral are available through Hirschfelder et al. (1964), (Table I-M, pp. 1126-1127, column 1). Thus binary diffusion coefficients may be calculated for all combinations of the gases listed.

\section{SIMPLIFICATION OF THEORY}

The mathematics of multinary gas diffusion is rather complicated. Therefore, we have tried to simplify the mathematical description of diffusion by the following reasoning. Assume that gases in a mixture diffuse independently of each other and that each molar flux can be calculated by Fick's first law

$$
N_{i}=-D_{i N_{2}} c \frac{d X_{i}}{d x}
$$


TABLE 2

Molecular weights and force constants for calculating binary diffusion coefficients according to Eqs. (4) through (6)

\begin{tabular}{lcccccc}
\hline \multicolumn{1}{c}{ Gas } & $\mathrm{Ne}$ & $\mathrm{Ar}$ & $\mathrm{Air}$ & $\mathrm{N}_{2}$ & $\mathrm{O}_{2}$ & $\mathrm{CO}_{2}$ \\
$M \times 10^{3} \mathrm{~kg} \mathrm{~mol}^{-1}$ & 20.17 & 39.95 & 28.97 & 28.01 & 32.00 & 44.01 \\
$\sigma_{i i} \times 10^{10} \mathrm{~m}^{a}$ & 2.789 & 3.418 & 3.617 & 3.681 & 3.433 & 3.996 \\
$\epsilon_{i i} / k \mathrm{~K}^{a}$ & 35.7 & 124.0 & 97.0 & 91.5 & 113.0 & 190.0 \\
\hline \multicolumn{1}{c}{ Gas } & \multicolumn{2}{c}{$\mathrm{CH}_{4}$} & $\mathrm{C}_{2} \mathrm{H}_{2}$ & $\mathrm{~N}_{2} \mathrm{O}$ & $\mathrm{NH}_{3}$ & $\mathrm{H}_{2} \mathrm{O}$ \\
$M \times 10^{3} \mathrm{~kg} \mathrm{~mol}^{-1}$ & 16.04 & 26.04 & 44.01 & 17.03 & 18.02 \\
$\sigma_{i i} \times 10^{10} \mathrm{~m}^{a}$ & 3.822 & 4.221 & 3.879 & 3.15 & 2.71 \\
$\epsilon_{i i} / k \mathrm{~K}^{a}$ & 137.0 & 185.0 & 220.0 & 358.0 & 506.0 \\
\hline
\end{tabular}

${ }^{a}$ Except for $\mathrm{NH}_{3}$ and $\mathrm{H}_{2} \mathrm{O}$, from Hirschfelder et al. (1964), pp. 1110-1112. $\mathrm{NH}_{3}$ and $\mathrm{H}_{2} \mathrm{O}$ from Monchick and Mason (1961), Tables 12 and 14, respectively.

The binary diffusion coefficients in Eq. (8) are related to nitrogen, because the main molecular interaction between the different gases will occur with this principal constituent of soil atmosphere. Different binary diffusion coefficients will give different gas fluxes at similar concentration gradients, in principle causing gradients in absolute pressure. However, gradients in absolute pressure in diffusing gas mixtures are usually immeasurably small (Marrero and Mason 1972), and the effect is that the total molar flow $\sum_{i=1}^{u} N_{i}$ is zero, thus maintaining isobaric conditions. But when $N_{i}$ is computed according to Eq. (8) their sum is not zero. Therefore, the corrected flux $N_{i, \text { corr }}$ is computed as follows

$$
N_{i, \text { corr }}=N_{i}-\left(\sum_{j=1}^{v} N_{j}\right) X_{i}
$$

By the minus sign in Eq. (9) and the fact that $\sum_{i=1}^{v} X_{i}=1$, the mass balance is maintained. A possible additional convective flux, $N_{\text {conv }}$, from gas production is added to this diffusive flux to obtain total flux $N_{i, \text { tot }}$.

$$
N_{i, \text { tot }}=N_{i \text {, corr }}+N_{\text {conv }} X_{i}
$$

In the simplified mathematical description of diffusion, Eqs. (8) through (10) in finite difference form replace Eq. (2) in the simulation model. This simplified theory is tested for the case study of denitrification.

\section{MODEL TESTS}

The correct implementation of the theory in the dynamic simulation model was ascertained by comparing its numerical results, obtained for particular sets of boundary conditions and at steady state, to corresponding analytical solutions. Steady-state analytical solutions to iso- thermal, isobaric, ordinary diffusion problems for ternary idea-gas mixtures for one-phase systems in one dimension have been given by, among others, Toor (1957) and Hsu and Bird (1960). To give examples of importance for soil research, gas mixtures are composed of the following gases: $\mathrm{O}_{2}, \mathrm{~N}_{2}, \mathrm{CO}_{2}, \mathrm{H}_{2} \mathrm{O}$-vapor, $\mathrm{N}_{2} \mathrm{O}$, or $\mathrm{C}_{2} \mathrm{H}_{2}$.

\section{Diffusion of $\mathrm{H}_{2} \mathrm{O}$-vapor through stagnant $\mathrm{O}_{2}$ and $\mathrm{N}_{2}$}

When water vapor diffuses away from a water table through a sterile soil, the other gases, $\mathrm{O}_{2}$ and $\mathrm{N}_{2}$, experience an absorption barrier (Toor 1957) at the water table due to their low solubility in water. Hence, the water table is considered impermeable to oxygen and nitrogen. At the onset of diffusion of water vapor into initially dry $\mathrm{O}_{2}-\mathrm{N}_{2}$ atmosphere, these gases will be pushed upward by the water vapor, because the system remains isobaric. Fairbanks and Wilke (1950) measured the time course of such displaced volumes of gas mixtures at the end of a long tube from the bottom of which a liquid was allowed to evaporate upward. From these data they derived the diffusion coefficient of the vapor in the mixture. Eventually, equal molar amounts of water vapor will enter and leave the gas layer, while oxygen and nitrogen are stagnant.

The molar water vapor flux into the first layer adjacent to the water table is calculated according to

$$
N_{1}=\left(\Delta c_{1} / \Delta x\right) /\left(-\sum_{\substack{j=1 \\ j \neq 1}}^{v}\left(\bar{c}_{j} /\left(\bar{c} \bar{D}_{1 j}\right)\right)\right)
$$

This equation is obtained from Eq. (2) if the oxygen and nitrogen fluxes equal zero. The gra- 
dients of oxygen $(i=2)$ and nitrogen $(i=3)$ in that layer may be calculated from $\Delta c_{i} / \Delta x=N_{1} \bar{c}_{i} /$ $\left(\bar{c} \bar{D}_{i 1}\right)$. Through the remaining part of the gas layer all gases can diffuse freely, but as the system will remain isobaric, the sum of the molar fluxes through all interfaces should equal the molar water vapor flux through the bottom of the gas layer. Thus, the additional equation necessary to solve Eq. (2) at each layer interface, except the first one, becomes $\sum_{i=1}^{v} N_{i}=N_{1}$. This is attained in the model by replacing the first row in the matrix of coefficients by $1 \mathrm{~s}$ and the corresponding right-hand-side element by $N_{1}$ from Eq. (11).

The analytical solution with respect to the steady-state molar water vapor flux, $N_{1}$, is implicitly given in

$$
X_{2}{ }^{0}=\left[1-\frac{1}{r}\left(\frac{\exp \left(\alpha_{12} r\right)-1}{\exp \left(\alpha_{12} r\right)-Q}\right)\left(\frac{\exp \alpha_{12}-Q}{\exp \alpha_{12}-1}\right)\right]^{-1}
$$

(Hsu and Bird 1960), where $\alpha_{12}=N_{1} \delta /\left(c D_{12}\right), r$ $=D_{12} / D_{13}, Q=\left(1-X_{1 \delta}\right) /\left(1-X_{10}\right)$, and $X_{2}{ }^{0}$ is the average mole-fraction of gas 2 , oxygen, before any water vapor has diffused into the gas layer. Equation (12) was solved for $N_{1}$ by an iterative procedure using as a first guess the steady-state flux from the simulation model. The analytical solution with respect to the steady-state mole-fraction profiles of the stagnant gases oxygen, $i=2$, and nitrogen, $i=3$, are obtained through integration of the StefanMaxwell equations $d X_{i} / d x=\left(N_{1} /\left(c D_{1 i}\right)\right) X_{i}$, subject to the boundary condition $X_{i}=X_{i}^{0}$ at $x=\delta$, yielding

$$
X_{i}=X_{i}^{0} \exp \left[N_{1}(x-\delta) /\left(c D_{1 i}\right)\right]
$$

Equation (13) shows that the mole-fraction profiles decrease exponentially from the top, $x=\delta$, to the bottom, $x=0$, of the gas layer.

The molar water vapor flux and mole-fraction profiles obtained by simulation after about 300 s, and analytically by Eqs. (12) and (13), are reported in Table 3 for the following conditions: $293 \mathrm{~K}, 1 \mathrm{~atm}, X_{10}=2.3094 \times 10^{-2}, X_{1 \delta}=0.0, X_{2}{ }^{0}$ $=X_{2 \delta}=0.2, X_{3}{ }^{0}=X_{3 \delta}=0.8, D_{12}=2.2251 \times$ $10^{-5} \mathrm{~m}^{2} \mathrm{~s}^{-1}, D_{13}=2.2082 \times 10^{-5} \mathrm{~m}^{2} \mathrm{~s}^{-1}, c=$ $41.5696 \mathrm{~mol} \mathrm{~m}^{-3}, \delta=0.05 \mathrm{~m}$. The binary diffusion coefficients between water vapor and oxygen and between water vapor and nitrogen, respectively, are almost equal, making the analytical solutions of Eqs. (12) and (13) sensitive to slight changes in the input parameters. Table 3 shows that results of the mole-fraction profiles and the molar water vapor flux as calculated by the simulation model and the analytical solution, respectively, do not differ more than $0.1 \%$. Note that although $\mathrm{O}_{2}$ and $\mathrm{N}_{2}$ possess concentration gradients, they are stagnant. This result indicates that if concentration profiles are used to predict fluxes, the interpretation of results in terms of Fick's first law would not be correct. As a consequence, calculations of gas fluxes from measured oxygen concentration profiles by means of Fick's first law, and soil respiration rates from the differences between these fluxes at different depths in soil as proposed by de Jong and Schappert (1972) for carbon dioxide, would result in overestimates of soil activity. To give an order of magnitude, oxygen consumption was calculated from the steady-state profile given in Table 3 as $3.5 \times 10^{-5} \mathrm{~mol} \mathrm{O}_{2} \mathrm{~m}^{-3} \mathrm{~s}^{-1}$ using the binary diffusion coefficient between oxygen and nitrogen from Table 1 . This value may be compared to respiration figures of de Jong and

TABLE 3

Comparison between model results and analytical results with respect to the steady-state mole-fraction profiles

\begin{tabular}{|c|c|c|c|c|}
\hline \multirow{2}{*}{$\begin{array}{l}\text { Relative height in gas } \\
\text { layer } x / \delta\end{array}$} & \multicolumn{2}{|c|}{ Simulation model } & \multicolumn{2}{|c|}{ Analytical solution } \\
\hline & \multicolumn{3}{|c|}{ mole-fraction } & $\mathrm{N}_{2}$ \\
\hline 0.95 & 0.199768 & 0.799064 & 0.199768 & 0.799065 \\
\hline 0.65 & 0.198379 & 0.793468 & 0.198381 & 0.793475 \\
\hline 0.35 & 0.197000 & 0.78791 & 0.197004 & 0.78792 \\
\hline \multirow[t]{2}{*}{0.05} & 0.195631 & 0.78239 & 0.195636 & 0.78241 \\
\hline & \multicolumn{4}{|c|}{$\mathrm{mol} \mathrm{m}^{-2} \mathrm{~s}^{-1}$} \\
\hline $\begin{array}{l}\text { Molar water vapor } \\
\text { flux }\end{array}$ & \multicolumn{2}{|c|}{$0.430110^{-3}$} & \multicolumn{2}{|c|}{$0.429610^{-3}$} \\
\hline
\end{tabular}
and the molar water vapor flux, respectively 
Schappert based on carbon dioxide profiles. The average value read from their Fig. 3 is about 1 $\times 10^{-5} \mathrm{~mol} \mathrm{CO}_{2} \mathrm{~m}^{-3} \mathrm{~s}^{-1}$. Thus the evaporating water already causes an oxygen profile that suggests a respiration rate much greater than that found in practice.

\section{Equimolar counterdiffusion through a stagnant third gas}

When steady-state conditions prevail in soil with respect to the exchange of carbon dioxide $(i=1)$ and oxygen $(i=2)$ with the atmosphere, the third gas, nitrogen $(i=3)$, is stagnant when Eqs. (14) and (15) are simultaneously satisfied (Toor 1957).

$$
\begin{gathered}
N_{1}=-N_{2}=\frac{1}{\left(\frac{1}{D_{13}}-\frac{1}{D_{23}}\right)} \frac{p}{R T x} \ln \left(\frac{X_{3 \delta}}{X_{30}}\right) \\
\left(1-\frac{D_{12}}{D_{23}}\right)\left(X_{10}-X_{1 \delta}\right)+\left(1-\frac{D_{12}}{D_{13}}\right) \\
\cdot\left(X_{20}-X_{2 \delta}\right)=\ln \left(\frac{X_{3 \delta}}{X_{30}}\right)
\end{gathered}
$$

Equation (14) gives the molar fluxes $N_{i}$ of components $\mathrm{CO}_{2}(i=1)$ and $\mathrm{O}_{2}(i=2)$ when the molar nitrogen flux ( $i=3$ ) equals 0 , but $N_{3}=0$ only when the mole fractions are related so as to satisfy Eq. (15). For a numerical evaluation of Eq. (15) the mole fractions of carbon dioxide, oxygen, and nitrogen at the surface of the gas layer, i.e., at $x=\delta$, are set equal to $0.0,0.2$, and 0.8 , respectively, and at depth $x=0$ the mole fraction of carbon dioxide is set equal to 0.1 . The binary diffusion coefficients for the relevant gas pairs, as obtained from the theoretical equations at $20^{\circ} \mathrm{C}$, are taken from Table 1 . The mole fraction of nitrogen at depth $x=0, X_{30}$, may be expressed as $1-X_{10}-X_{20}$. Subsequently, Eq. (15) may be solved by an iterative procedure, because the mole fraction of oxygen at $x=0$, $X_{20}$, is the only unknown left. For this example it is found that $X_{20}=0.1204$, and $X_{30}=0.7796$. The diffusion fluxes of carbon dioxide and oxygen can now be calculated from Eq. (14). At atmospheric pressure, a temperature of $20^{\circ} \mathrm{C}$, and a layer thickness of $0.05 \mathrm{~m}$, this yields $N_{1}=$ $-N_{2}=0.1223610^{-2} \mathrm{~mol} \mathrm{~m}^{-2} \mathrm{~s}^{-1}$. In this example all gases can diffuse freely through the gas layer, while the sum of the molar fluxes equals zero

$$
\sum_{i=1}^{v} N_{i}=0
$$

To compare the performance of the simulation model with the analytical solution, Eq. (2) was solved using this additional equation by replacing the first row in the matrix of coefficients by $1 \mathrm{~s}$ and the corresponding right-hand side by 0 . The model was run with the above-mentioned conditions.

The molar flux established for carbon dioxide was $N_{1}=0.1222610^{-2} \mathrm{~mol} \mathrm{~m}^{-2} \mathrm{~s}^{-1}$, which is but $0.08 \%$ lower than the analytical result. By this time, (after about $300 \mathrm{~s}$ ) the flux of molecular nitrogen was about $10^{-9} \mathrm{~mol} \mathrm{~m}^{-2} \mathrm{~s}^{-1}$. Nevertheless, this gas shows a concentration gradient of $17 \mathrm{~mol} \mathrm{~m}^{-4}$. Interpretation of this concentration gradient in terms of Fick's first law would cause a flux of $-0.2510^{-3} \mathrm{~mol} \mathrm{~m}^{-2} \mathrm{~s}^{-1}$ when the binary diffusion coefficient of the gas pair nitrogencarbon dioxide is used. Nitrogen experiences a so-called diffusion barrier (Toor 1957), indicating that the resistance of the gas layer to the transfer of nitrogen is infinite.

A third example (data not reported), where oxygen diffuses through the gas layer to form carbon dioxide at $x=0$, while nitrogen is stagnant after some time, also compared well to the appropriate analytical solution given by $\mathrm{Hsu}$ and Bird (1960).

From the good agreement between numerical and analytical solutions and the fact that the method of solving Eq. (2) is identical when more than three components are involved, it is concluded that the model can be used to study the dynamic behavior of more complex systems for which no analytical solutions are available.

\section{DENITRIFICATION; A CASE STUDY}

During denitrification nitrate serves as an electron acceptor for microorganisms at low oxygen concentrations, with the result that the gases $\mathrm{N}_{2} \mathrm{O}$ and $\mathrm{N}_{2}$ can be produced (Delwiche 1981). Direct field estimation of $\mathrm{N}_{2}$ emission is difficult because of the large concentration of $\mathrm{N}_{2}$ in the atmosphere. However, acetylene $\left(\mathrm{C}_{2} \mathrm{H}_{2}\right)$ inhibits the reduction of nitrous oxide to molecular nitrogen (Yoshinari et al. 1977). Therefore, estimates of nitrogen losses from soil can be obtained by measuring nitrous oxide, while acetylene is supplied to the soil atmosphere through probes inserted into soil (Ryden et al. 1979). From these probes acetylene has to diffuse through the macropore space and from there into the soil crumbs where denitrification is expected to occur (Leffelaar 1979; Smith 1980). 
The major question of interest in this case study is whether calculations of gas diffusion according to the Stefan-Maxwell equations yield significantly different results for respiration and denitrification compared with Fick's law. To assess this difference, acetylene is chosen as a measure because its dynamic behavior can also be calculated by an analytical solution (Crank 1975). As production of gases causes convection (Stolzy and Flühler 1978), acetylene will be pushed away from the sites where denitrification takes place. Therefore, subquestions of interest are: (1) can effective concentrations of acetylene be reached at locations in soil where denitrification takes place to inhibit the conversion of nitrous oxide to molecular nitrogen, without severely disturbing the soil atmosphere?; if so (2) what time does it take to reach such effective concentrations compared with estimates based on Fick's law?; and (3) what overall gas movement takes place in the profile due to net production of gases?

To investigate these questions the following system is studied. A soil layer $0.25 \mathrm{~m}$ thick and having linear geometry as depicted in Fig. 1 is subdivided into 10 equal layers. The soil surface, i.e., at $x=\delta$, is continuously supplied with a mixture of air and $2 \%$ of acetylene, while gaseous products of denitrification, nitrous oxide and molecular nitrogen, released from soil are continuously removed. Thus the gas composition at the soil surface for $\mathrm{O}_{2}, \mathrm{CO}_{2}, \mathrm{~N}_{2}$ from the atmosphere (subsequently called $\mathrm{N}_{2}{ }^{\text {at }}$ ), $\mathrm{C}_{2} \mathrm{H}_{2}$ added, $\mathrm{N}_{2} \mathrm{O}$, and $\mathrm{N}_{2}$ from denitrification is 20.0, $0.03,77.97,2.0,0.0$, and $0.0 \%$, respectively. As a first approximation biological activity is located in the deepest sublayer, i.e., layer 1 . Below this layer soil is impermeable to gases. The overlaying nine inert sublayers serve as a resistance to diffusion. The production terms $\left(P_{i}\right)$ in layer 1 are defined by Eqs. (16) through (22)

$$
\begin{gathered}
P_{\mathrm{O}_{2}}=-k_{1} r_{\mathrm{O}_{2}} \\
P_{\mathrm{CO}_{2}}=-P_{\mathrm{O}_{2}}+k_{2} c_{\mathrm{NO}_{3}}\left(1-r_{\mathrm{O}_{2}}\right) \\
P_{\mathrm{N}_{2}} \text { at }=0.0 \\
P_{\mathrm{C}_{2} \mathrm{H}_{2}}=0.0 \\
P_{\mathrm{N}_{2} \mathrm{O}}=0.5 k_{3} c_{\mathrm{NO}_{3}}\left(1-r_{\mathrm{O}_{2}}\right)-P_{\mathrm{N}_{2}} \\
P_{\mathrm{N}_{2}}=k_{4} c_{\mathrm{N}_{2} \mathrm{O}}\left(1-r_{\mathrm{O}_{2}}\right)\left(1-r_{\mathrm{C}_{2} \mathrm{H}_{2}}\right) \\
P_{\mathrm{NO}_{3}}=-k_{3} c_{\mathrm{NO}_{3}}\left(1-r_{\mathrm{O}_{2}}\right)
\end{gathered}
$$

where $k_{1}$ and $k_{2}, k_{3}, k_{4}$ are zeroth-order and first- order rate constants, respectively. Rate-limiting concentrations of oxygen and acetylene may occur. This is introduced in the equations by $r_{i}$, where $i$ refers to either oxygen or acetylene. It is assumed that $r_{i}$ is a linear function of gas concentration between a lower, $l_{i}$, and a higher, $h_{i}$, limit, as depicted in Fig. 3 . When nitrate is present and $l_{\mathrm{O}_{2}}<c_{\mathrm{O}_{2}}<h_{\mathrm{O}_{2}}$, both aerobic respiration and denitrification occur. Increasing denitrification activity with decreasing oxygen tension in continuous culture studies of $\mathrm{Hy}$ phomicrobium $\mathrm{X}$ was reported by Meiberg et al. (1980). When $l_{\mathrm{C}_{2} \mathrm{H}_{2}}<c_{\mathrm{C}_{2} \mathrm{H}_{2}}<h_{\mathrm{C}_{2} \mathrm{H}_{2}}$, the conversion of nitrous oxide to molecular nitrogen, Eq. (21), is partially inhibited. Partial inhibition of nitrous oxide reduction below $1 \%$ of acetylene in anaerobic moist soil was reported by Yoshinari et al. (1977). When $c_{\mathrm{O}_{2}}>h_{\mathrm{O}_{2}}, r_{\mathrm{O}_{2}}$ equals unity, and equimolar respiration takes place as shown by Eqs. (16) and (17).

Molecular nitrogen occurs both as the gas produced by denitrification, Eq. (21), and as atmospheric nitrogen. These gases with different origins are separately followed in the model. The additional equation to solve Eq. (2) at each sublayer interface except the first one is

$$
\sum_{i=1}^{v} N_{i}=N_{1}
$$

where $N_{1}$ is calculated from the net specific production rate $\left(\mathrm{mol} \mathrm{m} \mathrm{m}^{-3} \mathrm{~s}^{-1}\right)$, as obtained by the sum of $P_{i}$ of Eqs. (16) through (21) times the volume of the biologically active layer and divided by the surface area between layers 1 and 2.

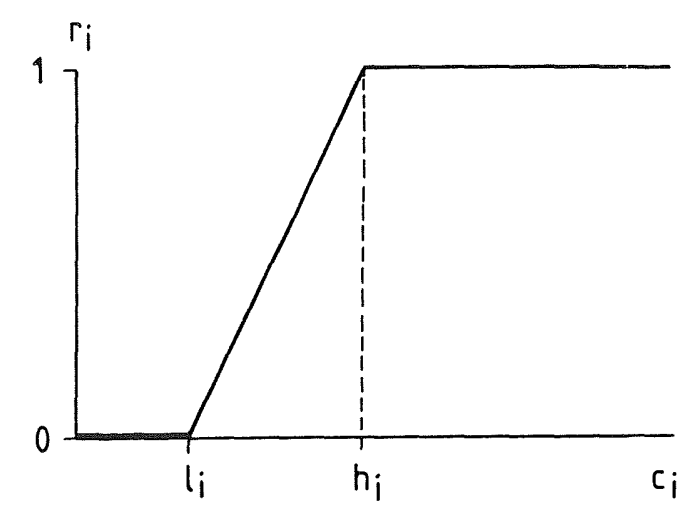

FIG. 3. General relationship between reduction factor and gas concentration. For numerical values of $l_{i}$ and $h_{i}$ see text. 


\section{Model parameters}

The zeroth-order rate constant $k_{1}=3.9510^{-4}$ mol $\mathrm{O}_{2} \mathrm{~m}^{-3} \mathrm{~s}^{-1}$ is based on work by Greenwood and Goodman (1964). These authors also indicated that respiration remains constant down to low values of oxygen concentration, thus supporting the assumption of a zeroth-order process. The first-order rate constant $k_{3}$ in Eq. (22) equals $6.5310^{-6} \mathrm{~s}^{-1}$. This value is derived from Avnimelech (1971), who reported nitrate disappearance as a function of initial concentration and temperature under conditions favorable for denitrification. Following Eq. (1) from Yoshinari et al. (1977), the reduction of 1 mole of nitrate will result in the production of 1 mole of carbon dioxide and 0.5 mole of nitrous oxide. Therefore $k_{2}$ in Eq. (17) is taken equal to $k_{3}$, and $k_{3}$ in Eq. (20) is multiplied by 0.5. Also, as a first approximation, rate constant $k_{4}$ is taken equal to $k_{3}$. The initial amount of nitrate is 88.6 $\mathrm{g} \mathrm{NO}_{3}{ }^{-} \mathrm{m}^{-2}\left(200 \mathrm{~kg} \mathrm{NO}_{3}{ }^{-} \mathrm{N} \mathrm{ha}^{-1}\right)$ located in the deepest soil layer. Nitrate is assumed to be effectively depleted when $0.5 \%$ of the initial amount is left. The lower and upper values of the concentrations of oxygen and acetylene in Fig. 3 are taken equivalent to 0.1 and $1.0 \%$, respectively. The gas fluxes defined in Eqs. (16) through (21) refer to the surface area of soil as a whole. To satisfy these fluxes at a gas-filled porosity of $\epsilon$, the fluxes inside the pores must be approximately $\epsilon^{-(4 / 3)}$ times as large (Millington 1959), where the factor $4 / 3$ combines both area reduction and tortuosity. To incorporate this effect on gas fluxes for $\epsilon=0.05$, the rate constants $k_{1}, k_{2}$, and $k_{4}$ were set higher by a factor of 50 . Rate constant $k_{3}$ was also multiplied by 50 to reduce computer time by increasing the nitrate depletion rate.

\section{Results and discussion of case study}

Figure 4 depicts the dynamics of the relative mole fraction of each gas and the relative convective flow in the biologically active deepest sublayer, i.e., layer 1. Absolute values of mole fraction or convective flow may be calculated from the curves by multiplying a specific value by its maximum, also given in Fig. 4 . The arrow in Fig. 4 separates two periods. In the first period $\mathrm{O}_{2}, \mathrm{CO}_{2}, \mathrm{~N}_{2}{ }^{\text {at }}$ and added $\mathrm{C}_{2} \mathrm{H}_{2}$ diffuse in the soil layer, while oxygen and carbon dioxide are involved in equimolar respiration. In the second period the oxygen concentration is smaller than $1 \%$ and denitrification occurs. Nitrous oxide and

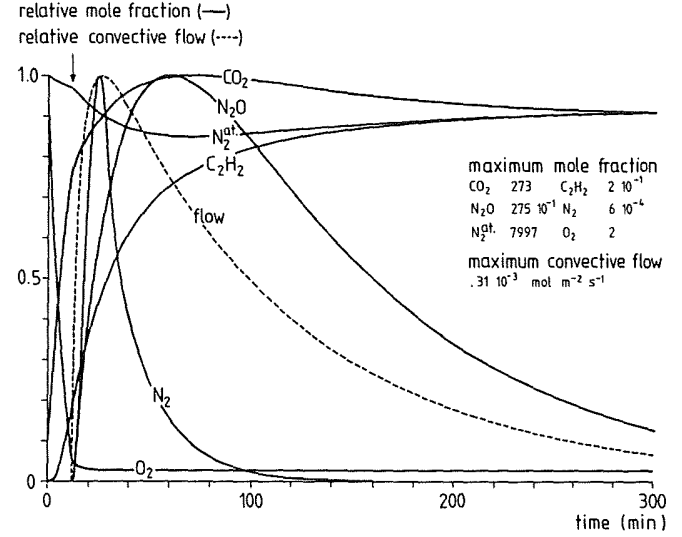

FIG. 4. Relative mole fractions of $\mathrm{O}_{2}, \mathrm{CO}_{2}, \mathrm{~N}_{2}{ }^{\text {at }}$, $\mathrm{C}_{2} \mathrm{H}_{2}, \mathrm{~N}_{2} \mathrm{O}$, and $\mathrm{N}_{2}$ (full lines) in sublayer 1 and relative convective flow (dashed line) through gas layer as a function of time.

molecular nitrogen are formed and cause a gas flow away from the active layer, because below this layer soil is impermeable. The influence of this convective flow on acetylene diffusion was evaluated by comparing its time course to results obtained by Eq. (4.17) of Crank (1975) (data not shown) using $D_{\mathrm{C}_{2} \mathrm{H}_{2}-\mathrm{N}_{2}}$ from Table 1 . This reveals that at the time of maximum convective flow the relative mole fraction of the simulated curve is about $14 \%$ lower. Furthermore, it takes $12 \%$ longer to reach the level of $1 \%$ acetylene. After the time of maximum convective flow, Crank's equation diverges strongly from the simulated result. At about $100 \mathrm{~min}$ a relative mole fraction of 0.97 is calculated, while in fact acetylene is seen to stabilize at about 0.9 at the end of the simulated period. Molecular nitrogen of atmospheric origin is partially removed from the soil profile. A maximum of $9 \%$ of the nitrogen initially present is removed at the time of the minimum in the $\mathrm{N}_{2}{ }^{\text {at }}$ curve. After this time the profile is partially replenished with atmospheric nitrogen. The time of occurrence of the minimum in the $\mathrm{N}_{2}{ }^{\text {at }}$ curve does not coincide with the time of maximum convective flow. However, the minimum in the $\mathrm{N}_{2}{ }^{\text {at }}$ curve coincides with the maxima in the $\mathrm{CO}_{2}$ and $\mathrm{N}_{2} \mathrm{O}$ curves. This implies that the overall movement of $\mathrm{N}_{2}{ }^{\text {at }}$ is not mainly determined by convective flow, but rather by the accumulation of gases as $\mathrm{CO}_{2}$ and $\mathrm{N}_{2} \mathrm{O}$. The fact that both $\mathrm{N}_{2}{ }^{\text {at }}$ and $\mathrm{C}_{2} \mathrm{H}_{2}$ do not reach their atmospheric values in the long run may also be explained by the accumulation of $\mathrm{CO}_{2}$ in the profile, as convective flow 
has become negligible by then. At the onset of denitrification the relative mole fractions of $\mathrm{N}_{2} \mathrm{O}$ and $\mathrm{N}_{2}$ increase rapidly. $\mathrm{N}_{2}$ is hardly formed as the level of $1 \%$ of $\mathrm{C}_{2} \mathrm{H}_{2}$ is quickly reached. Therefore, mainly $\mathrm{N}_{2} \mathrm{O}$ is formed. Observe that the maximum mole fraction of nitrous oxide appears much later than the maximum convective flow. As nitrous oxide is the principle cause of convective flow, both maxima would be expected to coincide. This result demonstrates the complex behavior of gas mixtures with mutually dependent diffusion fluxes and convective flow due to source/sink terms.

The questions stated earlier can now be answered. (1) Effective concentrations of acetylene may be reached in soil to inhibit the conversion of nitrous oxide into molecular nitrogen without severely disturbing the soil atmosphere. (2) The time to reach this concentration is about $12 \%$ longer compared with the usual calculations, e.g., Eq. (4.17) of Crank (1975). (3) Overall gas movement due to gas production and accumulation of gases as carbon dioxide and nitrous oxide amount to a maximum of $10 \%$ for atmospheric nitrogen. These figures show that acetylene diffusion is not seriously affected by describing the diffusion process by the StefanMaxwell equations.

The case study of denitrification was also used to test the simplified theory of gas diffusion as summarized in Eqs. (8) through (10). Results (data not reported) are very similar to those of the rigorous theory. The largest difference was found for the maximum nitrous oxide concentration, which was $8 \%$ lower, compared with the rigorous theory. This remarkable agreement may be ascribed to the similarity of binary diffusion coefficients, which do not differ by more than a factor of 2 . As a result, the correction term in Eq. (9) will be small compared with the concentration diffusion term, i.e., Eq. (8). This reasoning is supported by the fact that, for the limiting case of equal binary diffusion coefficients, both Eq. (2) and Eq. (9) reduce to Eq. (8). However, when diffusion of gases in multinary gas mixtures with largely different binary diffusion coefficients is to be investigated, the Stefan-Maxwell equations must be used.

\section{CONCLUSIONS}

1. The simulation model presented enables us to study the integral dynamics of diffusion processes in soil atmosphere.
2. Gas profiles showing concentration gradients may be stagnant for some components. Interpretation of such profiles in terms of calculations of gas fluxes at different depths and production terms from the differences between these gas fluxes would wrongly suggest nonzero production terms.

3. Denitrification is only slightly affected when the influence of a diffusion resistance on this process is calculated according to the Stefan-Maxwell equations, compared with Fick's law.

4. The Stefan-Maxwell equations as implemented in the simulation model must be used to study the dynamic behavior of gas mixtures whenever binary diffusion coefficients differ by more than a factor of 2 .

5. Simplified theory gives satisfactory results when binary diffusion coefficients do not differ by more than a factor of 2 and when one constituent of the gas phase is abundantly present, so that binary diffusion coefficients may be related to this component.

\section{SUMMARY}

Results of a dynamic simulation model describing diffusion of gases in multinary gas mixtures agree well with analytical steady-state solutions for ternary diffusion. This confirms the correct implementation of diffusion theory in the simulation model. Subsequently, the model has been used to calculate the dynamic behavior of a gas system in which denitrification takes place. Acetylene is taken as a measure of whether or not denitrification is significantly affected by describing the diffusion process by the Stefan-Maxwell equations, compared with an analytical solution to Fick's law. The case study then shows that denitrification is not significantly affected. The same case study is used to show that multinary diffusion can be well approximated by Fick's first law when modified to maintain isobaric conditions. In general, the simulation model based on the Stefan-Maxwell equations must be used to study the dynamic behavior of gas mixtures. However, simplified theory will give satisfactory results when binary diffusion coefficients do not differ by more than a factor of 2 , a condition usually met in the gas phase of soil.

The model is useful to gain insight into:

1. the dynamics of diffusion in complex gas systems containing sink/source terms 
2. the length of time to attain, if possible, a steady-state situation

3 . the order of magnitude of the gas fluxes through the profile

The computer program may be adapted easily to incorporate other kinetics of gas conversions, number of gases, and number of layers. The model will form part of an extended model including water flow and biological denitrification. This extended model should provide a means for calculating denitrification in soil aggregates not saturated with water and will be subject to integral verification by specially designed experiments.

\section{NOTE}

A listing of the computer program that produced these results is available from the author.

\section{ACKNOWLEDGMENTS}

I wish to express my appreciation to Prof. J. Schenk and Prof. H. J. Merk (Technical University of Delft) for stimulating discussions in the early stages of this work and to Prof. C. T. de Wit, Dr. J. Goudriaan, and Prof. G. H. Bolt for reviewing the manuscript.

\section{LIST OF SYMBOLS}

\begin{tabular}{|c|c|c|}
\hline Symbol & Meaning & Unit \\
\hline$a, b, c$ & $\begin{array}{l}\text { empirical constants in Eq. } \\
\text { (7) }\end{array}$ & \\
\hline$a$ & & $\mathrm{~Pa} \mathrm{~m} \mathrm{~s}^{-1}\left(\mathrm{~K}^{b}\right)^{-1}$ \\
\hline$c$ & & $\mathrm{~K}$ \\
\hline \multirow[t]{2}{*}{$c_{i}, c$} & $\begin{array}{l}\text { molar concentration of } \\
\text { component } i \text { and all com- } \\
\text { ponents together, } c_{i}=\rho_{i} / M_{i}\end{array}$ & $\mathrm{~mol} \mathrm{~m}^{-3}$ \\
\hline & $c=\sum_{i=1}^{v} c_{i}$ & \\
\hline$c_{L, i}$ & $\begin{array}{l}\text { molar concentration of } \\
\text { component } i \text { in layer } L\end{array}$ & $\mathrm{~mol} \mathrm{~m}^{-3}$ \\
\hline$D_{i j}$ & $\begin{array}{l}\text { binary diffusion coefficient } \\
\text { for gas pair } i-j\end{array}$ & $\mathrm{~m}^{2} \mathrm{~s}^{-1}$ \\
\hline$k$ & $\begin{array}{l}\text { Boltzmann constant, } k= \\
R / \tilde{N}=1.380510^{-23}\end{array}$ & $\mathrm{~J} \mathrm{~K}^{-1}$ \\
\hline & zeroth-order rate constant & $\mathrm{mol} \mathrm{m} \mathrm{m}^{-3} \mathrm{~s}^{-1}$ \\
\hline$k_{2}, k_{3}, k_{4}$ & first-order rate constants & $\mathrm{s}^{-1}$ \\
\hline$l_{i}, h_{i}$ & $\begin{array}{l}\text { lower and upper gas con- } \\
\text { centration limits where re- } \\
\text { duction factor } r_{i} \text { becomes } 0 \\
\text { and } 1 \text {, respectively }\end{array}$ & $\mathrm{mol} \mathrm{m}^{-3}$ \\
\hline$L$ & layer number & \\
\hline$M_{i}$ & $\begin{array}{l}\text { molecular weight of com- } \\
\text { ponent } i, M_{i}=\rho_{i} / c_{i}\end{array}$ & $\mathrm{~kg} \mathrm{~mol}^{-1}$ \\
\hline \multirow[t]{3}{*}{$n_{i}, n$} & $\begin{array}{l}\text { molecular concentration or } \\
\text { number density of compo- } \\
\text { nent } i \text { and all components } \\
\text { together }\end{array}$ & $\mathrm{m}^{-3}$ \\
\hline & $n_{i}=c_{i} \tilde{N}$ & \\
\hline & $n=\sum_{i=1}^{\nu} n_{i}$ & \\
\hline
\end{tabular}

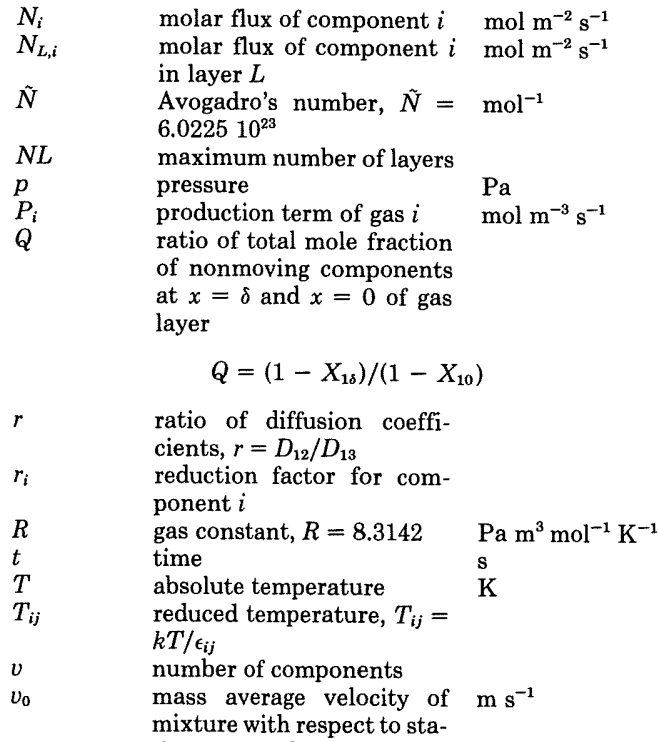

$$
v_{0}=\left(\sum_{i=1}^{\nu} \rho_{i} \bar{v}_{i}\right) /\left(\sum_{i=1}^{v} \rho_{i}\right)
$$

velocity of component $i \mathrm{~m} \mathrm{~s}^{-1}$

with respect to stationary coordinates, $\hat{v}_{i}=N_{i} / c_{i}$

$\bar{V}_{i} \quad$ diffusion velocity of com- $\mathrm{m} \mathrm{s}^{-1}$ ponent $i$ with respect to the mans average velocity of the mixture, $\bar{V}_{i}=\bar{v}_{i}-v_{0}$ distance between centers of $\mathrm{m}$

layers or space coordinate

$X_{i}, X_{i 0}, X_{i s}$ mole fraction of component $i$ in general and at $x=0$ and $x=\delta$ of gas layer, respectively

$X_{i}^{0} \quad$ mole fraction of component $i$ when no moving gas is present

$\alpha_{12}$ dimensionless quantity, $\alpha_{12}$ $=N_{1} \delta /\left(c D_{12}\right)$

total thickness of gas layer

finite difference of concerning symbol with respect to layers $L$ and $L-1$ gas-filled porosity

$\epsilon_{i i}, \epsilon_{i j} \quad$ Lennard-Jones potential $J$ parameter; maximum energy of attraction between like molecules of component $i$ and between unlike molecules of components $i$ and $j$

$\rho_{i}, \rho \quad$ mass concentration of com- $\mathrm{kg} \mathrm{m}^{-3}$ ponent $i$ and all components together, $\rho_{i}=c_{i} M_{i}$

$$
\rho=\sum_{i=1}^{\nu} \rho_{i}
$$

Lennard-Jones potential $\mathrm{m}$ parameter; collision diameter for like molecules of component $i$ and for unlike molecules of components $i$ and $j$ 
$\sum \quad$ summation operator

$\Omega_{i j} \quad$ dimensionless collision integral based on the Lennard-Jones intermolecular potential field

superscript; arithmetic spatial average of concerning symbol with respect to the layers $L$ and $L-1$

\section{REFERENCES}

Avnimelech, Y. 1971. Nitrate transformation in peat. Soil Sci. 111:113-118.

Crank, J. 1975. The mathematics of diffusion, 2nd ed. Oxford Univ. Press.

Cunningham, R. E., and R. J. J. Williams. 1980 Diffusion in gases and porous media. Plenum, New York.

Delwiche, C. C. (ed.). 1981. Denitrification, nitrification, and atmospheric nitrous oxide. Wiley, New York.

Fairbanks, D. F., and C. R. Wilke. 1950. Diffusion coefficients in multicomponent gas mixtures. Ind. Eng. Chem. 42:471-475.

Flühler, H., and H. P. Läser. 1975. A hydrophobic membrane probe for total pressure and partial pressure measurements in the soil atmosphere. Soil Sci. 120:85-91.

Frissel, M. J., and P. Reiniger. 1974. Simulation of accumulation and leaching in soils. Simulation Monographs, PUDOC, Wageningen, the Netherlands.

Greenwood, D. J., and D. Goodman. 1964. Oxygen diffusion and aerobic respiration in soil spheres. J. Sci. Food Agric. 15:579-588.

Hirschfelder, J. O., C. F. Curtiss, and R. B. Bird. 1964. Molecular theory of gases and liquids. Wiley, New York.

Hsu, H. W., and R. B. Bird. 1960. Multicomponent diffusion problems. Appl. Ind. Chem. Eng. J. 6:516-524.

IBM Corp. 1975. Continuous system modeling program III (CSMP III). Program reference manual. SH 19-7001-3. Data Processing Division, 1133 Westchester Ave., White Plains, N.Y.

Jaynes, D. B., and A. S. Rogowski. 1983. Applicability of Fick's law to gas diffusion. Soil Sci. Soc. Am. J. $47: 425-430$.

Jong, E. de, and H. J. V. Schappert. 1972. Calculation of soil respiration and activity from $\mathrm{CO}_{2}$ profiles in the soil. Soil Sci. 113:328-333.

Koorevaar, P., G. Menelik, and C. Dirksen. 1983. Elements of soil physics. Developments in Soil Science, 13. Elsevier, Amsterdam.

Kraner, H. W., G. L. Schroeder, and R. D. Evans. 1964. Measurement of the effects of atmospheric variables on radon-222 flux and soil-gas concentrations. In The natural radiation environment.
J. A. S. Adams and W. M. Lowder (eds.). Univ. of Chicago Press, Chicago, pp. 191-215.

La Fara, R. L. 1973. Computer methods for science and engineering. Hayden, Rochelle Park, N.J.

Leffelaar, P. A. 1979. Simulation of partial anaerobiosis in a model soil in respect to denitrification. Soil Sci. 128:110-120.

Marrero, T. R., and E. A. Mason. 1972. Gaseous diffusion coefficients. J. Phys. Chem. Ref. Data $1: 3-118$.

Mason, E. A., and L. Monchick. 1962. Transport properties of polar-gas mixtures. J. Chem. Phys. 36:2746-2757.

Meiberg, J. B. M., P. M. Bruinenberg, and W. Harder. 1980. Effect of dissolved oxygen tension on the metabolism of methylated amines in Hyphomicrobium $\mathrm{X}$ in the absence and presence of nitrate: Evidence for "aerobic" denitrification. J. Gen. Microbiol. 120:453-463.

Millington, R. J. 1959. Gas diffusion in porous media. Science 130:100-102.

Monchick, L., and E. A. Mason. 1961. Transport properties of polar gases. J. Chem. Phys. 35:16761697.

Ryden, J. C., L. J. Lund, J. Letey, and D. D. Focht. 1979. Direct measurement of denitrification loss from soils: 2. Development and application of field methods. Soil Sci. Soc. Am. J. 43:110-118.

Smith, K. A. 1980. A model of the extent of anaerobic zones in aggregated soils, and its potential application to estimates of denitrification. J. Soil Sci. 31:263-277.

Stolzy, L. H., and H. Flühler. 1978. Measurement and prediction of anaerobiosis in soils. In Nitrogen in the environment, vol. 1. D. R. Nielsen and J. G. MacDonald (eds.). Academic Press, New York, pp. 363-426.

Toor, H. L. 1957. Diffusion in three component gas mixtures. Appl. Ind. Chem. Eng. J. 3:198-207.

Wakao, N., S. Otani, and J. M. Smith. 1965. Significance of pressure gradients in porous materials: 1. Diffusion and flow in fine capillaries. Appl. Ind. Chem. Eng. J. 11:435-439.

Wakao, N., and J. M. Smith. 1962. Diffusion in catalyst pellets. Chem. Eng. Sci. 17:825-834.

Wilke, C. R. 1950. Diffusional properties of multicomponent gases. Chem. Eng. Prog. 46:95-104.

Wit, C. T. de, and H. van Keulen. 1975. Simulation of transport processes in soils. Simulation Monographs, PUDOC, Wageningen, the Netherlands.

Wood, J. T., and D. J. Greenwood. 1971. Distribution of carbon dioxide and oxygen in the gas phase of aerobic soils. J. Soil Sci. 22:280-288.

Yoshinari, T., R. Hynes, and R. Knowles. 1977. Acetylene inhibition of nitrous oxide reduction and measurement of denitrification and nitrogen fixation in soil. Soil Biol. Biochem. 9:177-183. 